\title{
Geographical and temporal origins of Neocaridina species (Decapoda: Caridea: Atyidae) in Taiwan
}

\author{
Chiao-Chuan Han ${ }^{1,2^{*}}$, Kui-Ching Hsu ${ }^{3}$, Lee-Shing Fang ${ }^{4,5}$, I-Ming Cheng ${ }^{6}$ and Hung-Du Lin ${ }^{7^{*}}$ (D
}

\begin{abstract}
Background: The freshwater species on Taiwan Island have been documented to have originated from mainland China and the Japanese islands from multiple events and by multiple colonization routes. Moreover, the sequences from the mitochondrial DNA cytochrome c oxidase subunit I (COI) have been used for DNA barcoding to identify the species. This study used the COI sequences to identify Neocaridina species in Taiwan and to examine their geographical and temporal origins.

Results: In total, 479 specimens were collected from 35 localities, which covered almost all rivers in Taiwan. In addition, some sequences were downloaded from GenBank. The maximum likelihood (ML) tree displayed that all sequences were sorted into 13 taxa (clades), and all sequences in Taiwan were sorted into four clades. The Bayesian skyline plots revealed that these four Neocaridina species have declined recently in Taiwan.

Conclusions: All results support that (1) there are four Neocaridina species in Taiwan, which are N. davidi, N. saccam, N. ketagalan and an undescribed Neocaridina species (N. sp.); (2) these four species colonized Taiwan Island in four colonization events; (3) N. sp. colonized Taiwan first; (4) after the island reached its shape, N. ketagalan and N. saccam colonized Taiwan from the Japanese islands and mainland China, respectively; (5) N. davidi colonized northern Taiwan last; and (6) the cyclic glacial and landform changes in East Asia shaped the colonization events and population structures of the Neocaridina species.
\end{abstract}

Keywords: DNA barcoding, Neocaridina, Origin, Phylogeography, Approximate Bayesian computation

\section{Background}

The genus Neocaridina Kubo, 1938, is a group of landlocked species of the family Atyidae that consists of 26 species and is distributed in East Asia [1, 2]. Based on the Taiwanese atyid shrimp fauna [3, 4], only one species, $N$. denticulate, is distributed throughout Taiwan Island. Shih and Cai [5] proposed two new species, $N$. saccam and $N$. ketegalan, in southern and northern Taiwan, respectively. However, Shin and Cai [5] only sampled the specimens of $N$. ketegalan in one population and that of $N$. saccam in the two populations. Thus, our study aimed to determine how many Neocaridina

\footnotetext{
* Correspondence: hancc@nmmba.gov.tw; varicorhinus@hotmail.com ${ }^{1}$ National Museum of Marine Biology and Aquarium, Pingtung 944, Taiwan ${ }^{7}$ The Affiliated School of National Tainan First Senior High School, Tainan 701, Taiwan

Full list of author information is available at the end of the article
}

species are present in Taiwan as well as the distribution pattern of each species.

Taiwan Island is located off the southeastern coast of mainland China and is separated from China by the shallow Taiwan Strait. Taiwan was first isolated from the mainland by rising sea levels four to five million years ago (mya) and reached its present shape ca. 2 mya [6]. Previous biogeographic studies support that the many freshwater species easily migrated from the mainland to the island during the Pliocene and Pleistocene glaciations as a result of the lowered sea level [7-10]. Geological evidence indicates that during the glaciations, the land bridges connected Taiwan Island to the Asian continent three to four times, initially during the Pliocene glaciation and potentially two to three times during the Pleistocene glaciation [11, 12]. In addition, during the early and late Pleistocene, the sea basins of East Asia were exposed and Korea, the Japanese islands, Taiwan Island and mainland China connected [13, 14]. During 
these ice ages, the migrations between the Asian mainland and Taiwan, Ryuku Archipelago, and Japan may have been possible across the land bridges $[15,16]$. Previous phylogeographical studies $[9,17,18]$ have suggested that freshwater species in Taiwan might have originated from mainland China and Japan through multiple events and by multiple colonization routes.

Previous phylogeographic studies [18-20] have suggested that many geological barriers, e.g., the Central Range, Miaoli Plateau, and Kaoping foreland basins, shaped the structures and distribution patterns of the fauna in Taiwan Island. Taiwanese orogeny (mountain building) uplifted the longitudinal Central Range to nearly $4000 \mathrm{~m}$ (Fig. 1). The distribution patterns and phylogeographic studies of freshwater fishes $[10,19]$ indicate that the Central Range may have acted as a barrier to dispersal between the western and eastern populations. Lin [21] proposed that the Miaoli Plateau emerged at 0.150 mya based on geological studies, and many studies suggest that the Miaoli Plateau isolated freshwater fishes, preventing dispersal $[9,19]$. The Kaoping foreland basins located in the southeastern Taiwan Strait reached a depth of $200 \mathrm{~m}$ within $3 \mathrm{~km}$ of the shoreline [22]. Previous studies [23-25] have proposed that this sea trench interrupted the extension of the Kaoping River towards the land bridge during the glaciations. In other words, even during the ice ages, the freshwater species south of the Kaoping River could not cross the Kaoping foreland basins to the north of the land bridge (Fig. 1).

According to geological history [11-14] and phylogeographic studies $[9,17,18,26]$, our study found that freshwater species colonized Taiwan Island from the Japanese islands or mainland China, once or multiple times, and through one or multiple routes. Moreover, the distribution patterns of the freshwater species were contributed by the origins of the colonization events and the colonization routes and times $[9,19]$. Thus, our study also wanted to determine the distribution range of each Neocaridina species and their origins and phylogeographic patterns in Taiwan. To address the above problems, the mitochondrial DNA (mtDNA) cytochrome c oxidase subunit I (COI) was used to investigate the genetic diversity and structure of the Neocaridina species in Taiwan. The sequences of mtDNA are usually analysed in studies of animal phylogeography $[9,23,27]$. Among all the mtDNA genes, the COI gene is a widely accepted marker for resolving taxonomic identity and evaluating the levels of genetic diversity and differentiation in Decapoda species $[28,29]$. The major questions in our study are (1) how many Neocaridina species are there in Taiwan, and (2) what is the colonization history of the Neocaridina species in Taiwan?

\section{Results}

\section{Species diversity in Taiwan}

Based on all COI sequence data in our study (Table 1) and Shih et al. [5] from GenBank, the ML tree (Fig. 2) displayed that all sequences were assorted into 13 taxa (clades), and all sequences in Taiwan were assorted into four clades. The sequences of $N$. davidi in Taiwan, Kineme, Japan and Hawaii were grouped together and were close to those of $N$. denticulata in Japan. The sequences from the mainland (populations $\mathrm{CJ}$ and $\mathrm{HJ}$ ) were assorted into three species [N. koreana, $N$. palmata, and one undescribed species $(N$.

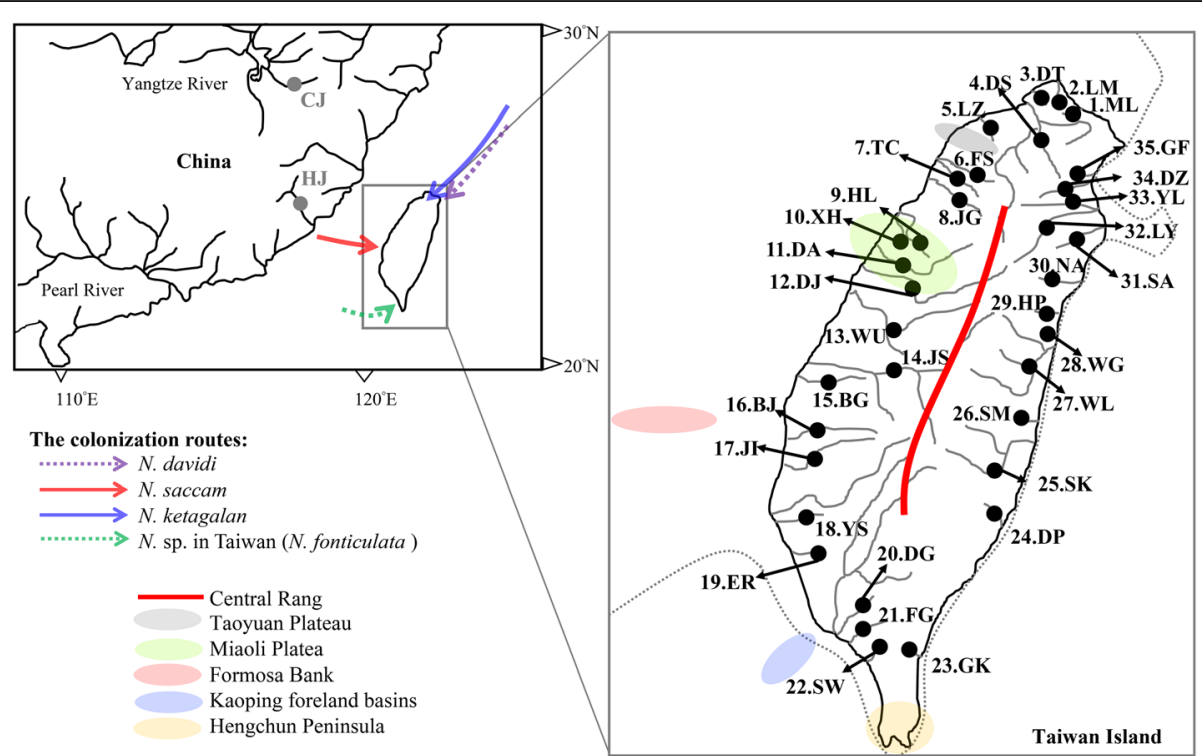

Fig. 1 The sampling localities of the Neocaridina species in Taiwan are indicated by . Possible colonization routes are displayed by arrows 
Table 1 Samples used for mtDNA analysis, species, location, code and summary statistics. The number of the private haplotypes (P) and the distribution information of shared haplotypes (S). For sample site number see Fig. 1

\begin{tabular}{|c|c|c|c|c|c|c|c|}
\hline \multirow{2}{*}{$\begin{array}{l}\text { Species/ } \\
\text { Population }\end{array}$} & \multirow[t]{2}{*}{ Code } & \multirow{2}{*}{$\begin{array}{l}\text { Sample } \\
\text { size }\end{array}$} & \multirow{2}{*}{$\begin{array}{l}\text { Haplotype } \\
\text { diversity } \\
\text { (h) }\end{array}$} & \multirow[t]{2}{*}{$P$} & \multirow[t]{2}{*}{$\mathrm{S}$} & \multicolumn{2}{|c|}{ Nucleotide diversity } \\
\hline & & & & & & $\pi(\%)$ & $\theta(\%)$ \\
\hline N. davidi & & 263 & 0.88 & & & 0.75 & 1.47 \\
\hline Malain & $1 . \mathrm{ML}$ & 16 & 0.23 & 2 & - & 0.04 & 0.05 \\
\hline Datun & 3.DT & 2 & 1.00 & 2 & - & 1.40 & 1.40 \\
\hline Danshuei & 4.DS & 23 & 0.61 & 2 & D4, D10 & 0.27 & 0.30 \\
\hline Fongshan & 6.FS & 6 & 0.73 & 1 & D7, D9 & 0.42 & 0.34 \\
\hline Touqian & 7.TC & 12 & 0.44 & 2 & D7 & 0.07 & 0.10 \\
\hline Jhonggang & 8.JG & 1 & - & 0 & D7 & - & - \\
\hline Houlong & $9 . \mathrm{HL}$ & 5 & 0.40 & 0 & D2, D9 & 0.13 & 0.15 \\
\hline Daan & 11.DA & 15 & 0.83 & 2 & D2, D3, D9 & 0.38 & 0.34 \\
\hline Dajia & 12.DJ & 6 & 0.80 & 4 & - & 0.26 & 0.34 \\
\hline Wu & 13.WU & 6 & 0.33 & 1 & D9 & 0.05 & 0.07 \\
\hline Jhuoshuei & 14.JS & 15 & 0.34 & 0 & D3, D9 & 0.05 & 0.05 \\
\hline Donggang & $20 . D G$ & 6 & - & 0 & D1 & - & - \\
\hline Fengkong & 21.FG & 18 & 0.58 & 2 & D10 & 0.25 & 0.32 \\
\hline Shiwen & $22.5 W$ & 1 & - & 0 & D6 & - & - \\
\hline Gangkong & 23.GK & 11 & 0.44 & 0 & D1, D6 & 0.07 & 0.05 \\
\hline Dapo & 24.DP & 12 & 0.17 & 0 & D8, D9 & 0.03 & 0.05 \\
\hline Siuguluan & 25.SK & 23 & 0.52 & 0 & D8, D9 & 0.08 & 0.04 \\
\hline Hualien & 27.WL & 24 & 0.16 & 0 & D8, D9 & 0.03 & 0.04 \\
\hline Hualiengang & 28.WG & 12 & - & 0 & D9 & - & - \\
\hline Heping & 29.HP & 2 & - & 0 & D5 & - & - \\
\hline Naoao & 30.NA & 6 & 0.60 & 0 & D5, D11 & 0.19 & 0.14 \\
\hline Suao & 31.SA & 5 & 0.40 & 2 & - & 0.19 & 0.23 \\
\hline Lanyang & 32.LY & 6 & 0.60 & 1 & D4 & 0.09 & 0.07 \\
\hline Yilan & 33.YL & 18 & 0.87 & 6 & D10, D11 & 0.60 & 0.77 \\
\hline Dezi & 34.DZ & 6 & 0.60 & 3 & - & 0.24 & 0.27 \\
\hline Gengfang & 35.GF & 6 & 0.73 & 3 & - & 0.31 & 0.27 \\
\hline N. sp. & & 43 & 0.64 & & & 0.33 & 1.12 \\
\hline Siuguluan & 25.SK & 13 & 0.53 & 3 & N1 & 0.78 & 1.46 \\
\hline Sihmen & $26.5 M$ & 12 & - & 1 & - & - & - \\
\hline Hualien & 27.WL & 18 & 0.37 & 1 & N1 & 0.06 & 0.05 \\
\hline N. saccam & & 47 & 0.81 & & & 0.91 & 0.64 \\
\hline Jhuoshuei & 14.JS & 15 & 0.68 & 3 & S2 & 0.16 & 0.14 \\
\hline Beigang & $15 . B G$ & 3 & - & 0 & S2 & - & - \\
\hline Bajhang & 16.BJ & 6 & - & 0 & S1 & - & - \\
\hline Jishuei & ال17.17 & 6 & - & 0 & S1 & - & - \\
\hline Yanshuei & 18.YS & 1 & - & 0 & S3 & - & - \\
\hline Erren & 19.ER & 16 & 0.34 & 2 & S3 & 0.13 & 0.19 \\
\hline N. ketagalan & & 126 & 0.95 & & & 0.99 & 1.30 \\
\hline Malain & $1 . \mathrm{ML}$ & 7 & 0.29 & 2 & - & 0.49 & 0.70 \\
\hline Laomei & $2 . L M$ & 7 & 0.71 & 2 & $\mathrm{~K} 2$ & 0.13 & 0.13 \\
\hline Datun & 3.DT & 10 & 0.53 & 4 & - & 0.16 & 0.28 \\
\hline
\end{tabular}


Table 1 Samples used for mtDNA analysis, species, location, code and summary statistics. The number of the private haplotypes (P) and the distribution information of shared haplotypes (S). For sample site number see Fig. 1 (Continued)

\begin{tabular}{|c|c|c|c|c|c|c|c|}
\hline \multirow{2}{*}{$\begin{array}{l}\text { Species/ } \\
\text { Population }\end{array}$} & \multirow[t]{2}{*}{ Code } & \multirow{2}{*}{$\begin{array}{l}\text { Sample } \\
\text { size }\end{array}$} & \multirow{2}{*}{$\begin{array}{l}\text { Haplotype } \\
\text { diversity } \\
\text { (h) }\end{array}$} & \multirow[t]{2}{*}{$P$} & \multirow[t]{2}{*}{ S } & \multicolumn{2}{|c|}{ Nucleotide diversity } \\
\hline & & & & & & $\pi(\%)$ & $\theta(\%)$ \\
\hline Danshuei & 4.DS & 31 & 0.75 & 5 & K2 & 0.52 & 0.47 \\
\hline Luzhou & $5 . L Z$ & 12 & - & 1 & - & - & - \\
\hline Jhonggang & 8.JG & 6 & 0.53 & 2 & - & 0.08 & 0.06 \\
\hline Houlong & $9 . \mathrm{HL}$ & 12 & 0.53 & 1 & K1 & 0.08 & 0.05 \\
\hline Xihu & $10 . \mathrm{XH}$ & 14 & 0.28 & 1 & $\mathrm{~K} 3, \mathrm{~K} 4$ & 0.13 & 0.29 \\
\hline Daan & 11.DA & 15 & 0.60 & 2 & $\mathrm{~K} 1, \mathrm{~K} 3$ & 0.32 & 0.24 \\
\hline Dajia & 12.DJ & 12 & 0.71 & 3 & K4 & 0.23 & 0.26 \\
\hline total & & 479 & & & & & \\
\hline
\end{tabular}

sp. in China)]. The range of the pairwise genetic distance between these 13 clades of Neocaridina (Fig. 2) was from $2.87 \%$ (between $N$. davidi and $N$. denticulata) to $15.23 \%$ (between $N$. sp. in Japan and N. spinose) (Table 2). The average pairwise genetic distance was $8.19 \%$. These results suggested that there were four Neocaridina species in Taiwan: N. davidi (clade 1), N. saccam (clade 6), N. ketagalan (clade 12) and one undescribed species ( $N$. sp. in Taiwan; clade 9). Neocaridina davidi was distributed widely; N. saccam was distributed in central and southern Taiwan; $N$. ketagalan was distributed in northern and southern Taiwan; and $N$. sp. was only distributed in eastern Taiwan (Fig. 2).

\section{Population and demographic history}

Although the phylogeny of the Neocaridina species (Fig. 2) displayed that there were four species in Taiwan, this study attempted to understand the colonization routes of these four species. Thus, this study proposed seven population

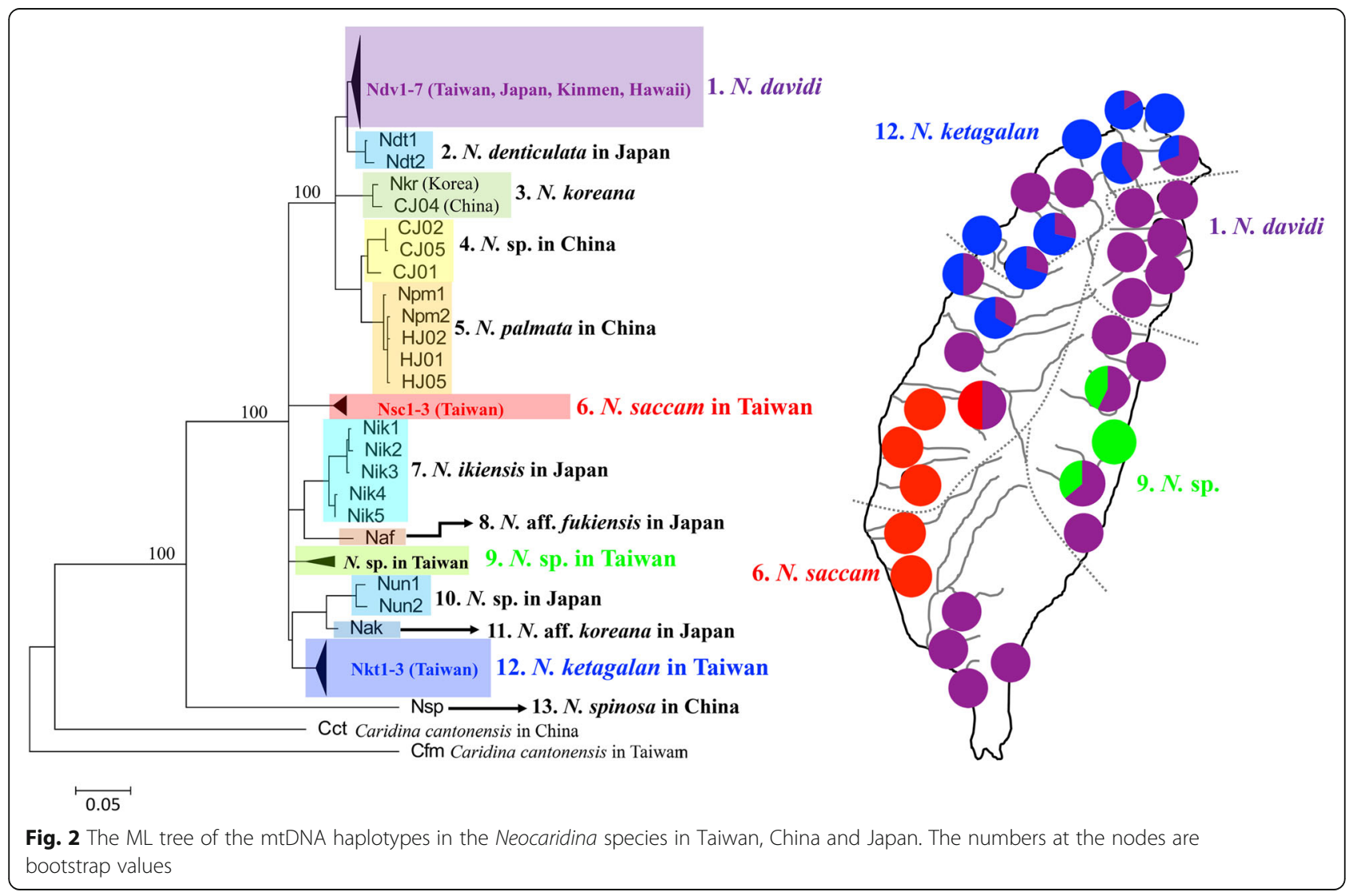


Table 2 Matrix of the percentage of pairwise nucleotide divergences ( $p$-distance) based on COI between clades of Neocaridina in Fig. 2

\begin{tabular}{|c|c|c|c|c|c|c|c|c|c|c|c|c|}
\hline & 2 & 3 & 4 & 5 & 6 & 7 & 8 & 9 & 10 & 11 & 12 & 13 \\
\hline 1. N. davidi & 2.87 & 4.90 & 5.08 & 4.96 & 7.08 & 7.18 & 8.04 & 7.50 & 9.10 & 7.52 & 6.68 & 13.00 \\
\hline 2. N. denticulata & & 4.84 & 5.80 & 5.29 & 7.59 & 7.19 & 8.50 & 8.27 & 9.20 & 8.19 & 7.26 & 13.50 \\
\hline 3. N. koreana & & & 5.72 & 5.88 & 8.32 & 8.21 & 9.20 & 8.09 & 9.83 & 8.58 & 7.11 & 13.81 \\
\hline 4. N. sp. (China) & & & & 3.49 & 7.23 & 8.28 & 9.46 & 8.04 & 9.67 & 8.42 & 7.70 & 13.29 \\
\hline 5. N. palmata & & & & & 7.98 & 8.05 & 8.86 & 8.22 & 9.92 & 8.64 & 7.17 & 14.13 \\
\hline 6. N. saccam & & & & & & 7.28 & 8.31 & 6.91 & 7.82 & 6.51 & 5.74 & 13.36 \\
\hline 7. N. ikiensis & & & & & & & 5.62 & 6.36 & 6.61 & 6.55 & 5.95 & 13.94 \\
\hline 8. N. aff. Fukiensis & & & & & & & & 6.99 & 7.80 & 7.18 & 6.64 & 14.44 \\
\hline 9. N. sp. (Taiwan) & & & & & & & & & 7.11 & 6.16 & 5.95 & 13.32 \\
\hline 10. N. sp. (Japan) & & & & & & & & & & 3.74 & 7.19 & 15.23 \\
\hline 11. N. aff. Koreana & & & & & & & & & & & 5.49 & 14.13 \\
\hline 12. N. ketagalan & & & & & & & & & & & & 13.70 \\
\hline 13. N. spinosa & & & & & & & & & & & & \\
\hline
\end{tabular}

history scenarios with the program DIYABC to understand the colonization history of the Neocaridina species in Taiwan. In the first scenario (scenario A), which was based on the phylogenetic analysis (Fig. 2), these four species arrived in Taiwan via four different colonization events (Fig. 3a). Under scenarios B-D, according to a previous study [26], the freshwater fish in eastern Taiwan arrived from western Taiwan. Thus, we proposed that $N$. sp. might have originated from the other three species (Figs. 3b-d).
Scenario E (Fig. 3e) showed that these four species colonized Taiwan by one colonization route and then diverged. In scenario F (Fig. 3f), N. ketagalan, N. saccam and N. sp. colonized Taiwan by the same colonization route and then diverged because these three species were allopatric. Finally, scenario G (Fig. 2g) showed that two species from northern Taiwan, $N$. davidi and $N$. ketagalan, colonized from one origin, and $N$. saccam and $N$. sp. colonized from another origin. The highest posterior probability was found for

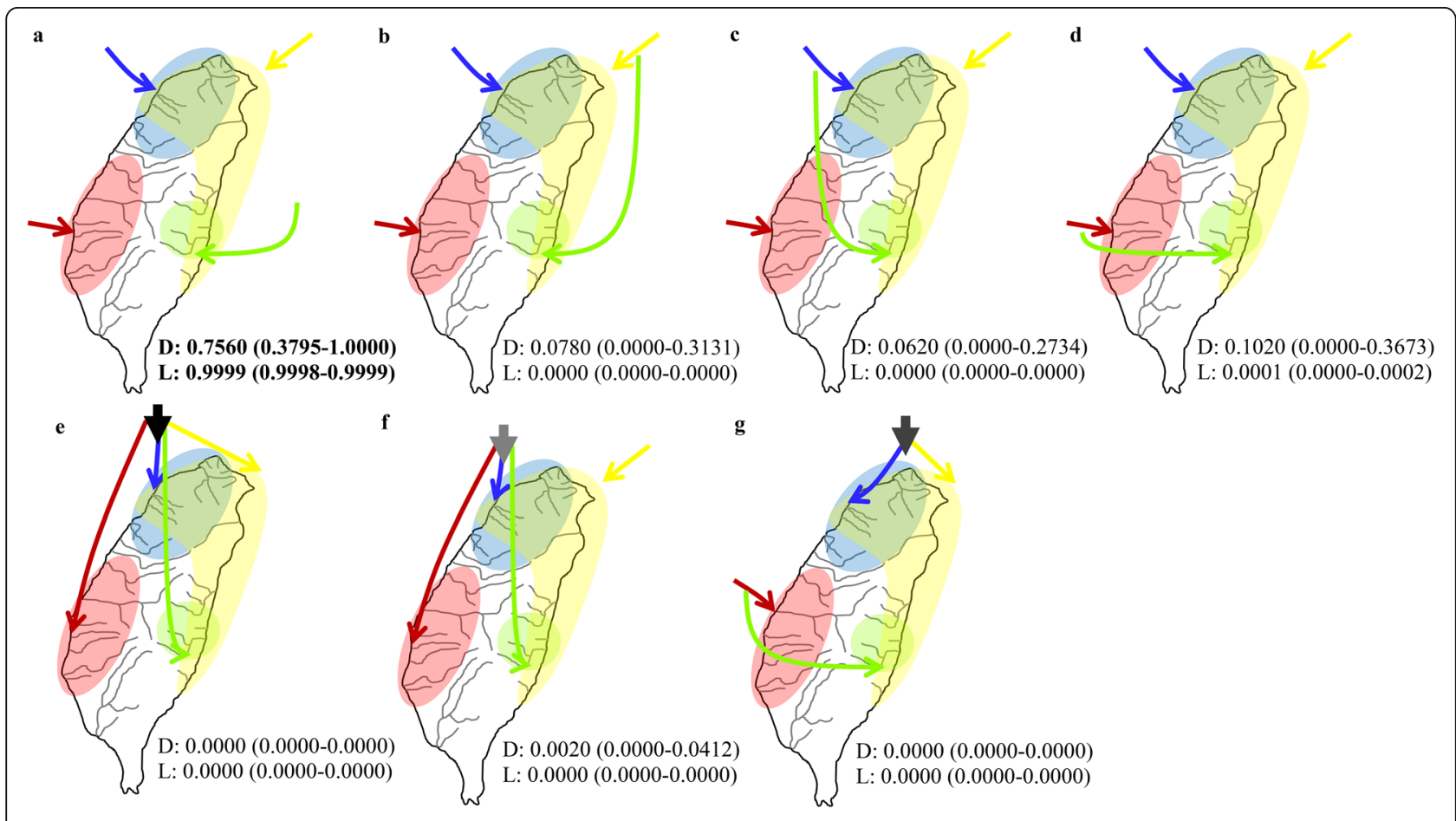

Fig. 3 Graphical representation of the DIYABC analyses 
scenario A. Its posterior probability (D: 0.7560 , 95\% CI: 0.3795-1.0000; L: 0.9999, 95\% CI: 0.9998-0.9999) was much higher than those of the other scenarios. The 95\% CI of scenario A did not overlap with those for the other scenarios (Fig. 3). Thus, the Neocaridina species in Taiwan might have colonized the area through four different events.

The time to coalescence was estimated in the BEAST analyses using two substitution rates: $2.33 \%$ per million years $[2,5,30]$ and $1.1 \%$ per million years [31]. The $\mathrm{T}_{\text {MRCA }}$ of these four species, $N$. davidi, $N$. ketagalan, $N$. saccam and $N$. sp., were 0.242-0.532, 0.37-0.774, $0.432-0.938$ and $1.021-2.180$, respectively (Table 3 ). However, the estimated Tajima's D and Fu's Fs values were largely consistent within each species; excluding $N$. sp. (Table 3), none of the calculated values supported population expansion. Although the statistical analysis of the species-specific mismatch distributions (the SSD and $\mathrm{Rg}$ indices) revealed that the observed distributions were not significantly different from those expected under a sudden expansion model for all species (Table 3), the Bayesian skyline plots revealed that these four Neocaridina species declined recently in Taiwan (Fig. 4).

\section{Population diversity of $N$. davidi in Taiwan}

A total of $44 N$. davidi COI haplotypes (641 bp) from 263 sequences were defined by 53 variable sites and 35 phylogenetically informative sites. The nucleotide sequences were $\mathrm{A}+\mathrm{T}$ rich $(60.0 \%)$. The mean COI haplotype diversity in each population was 0.47 (range: 0.00 to 1.00) (Table 1). The estimates of the current $\left(\theta_{\pi}\right)$ and historical $\left(\theta_{\omega}\right)$ genetic diversity of each population indicated that most populations showed a pattern of decline $\left(\theta_{\pi}<\theta_{\omega}\right)$ (Table 1). A comparison of the fixation indices $N_{\mathrm{ST}}$ and $G_{\mathrm{ST}}$ revealed that $N_{\mathrm{ST}}$ was larger than $G_{\mathrm{ST}}$ (0.72 and 0.47, respectively; Table 3 ). This result suggested a very weak relationship between phylogeny and geography.
Among the 44 COI haplotypes, eleven haplotypes (D1D11) were shared between two or more populations (Table 1). The most widespread haplotype was D9, which was distributed among nine populations. Among the 26 sampling populations, only one population (DA) had more than two shared haplotypes, and six populations (ML, DT, DJ, SA, DZ and GF) did not have any shared haplotypes. The population DA had the most shared haplotypes (D2, D3 and D9; Table 1). In the phylogenetic analyses, the haplotype trees reconstructed with different methods (ML and $\mathrm{BI}$ ) were identical. In the BI tree (Fig. 5a), 44 mtDNA haplotypes fell into three lineages (ND1-ND3). Lineage ND1 included 15 populations that were widespread in Taiwan, lineage ND2 contained five populations in northern Taiwan, and lineage ND3 contained nine populations in northern, eastern and southern Taiwan (Fig. 5a).

To detect the ancestral region of $N$. davidi in Taiwan, all sampling populations were sorted into five regions as in previous studies: northern (A), central (B), southern $(C)$, northeastern (E), and eastern (D) Taiwan [10, 32]. The results of the S-DIVA analysis produced a scenario with dispersion and vicariance events that shaped the current distribution patterns of $N$. davidi in Taiwan (Fig. $5 \mathrm{a})$. The ancestral populations of $N$. davidi were distributed in northern, central and northeastern Taiwan and then diverged and dispersed widely in Taiwan.

\section{Population diversity of $\boldsymbol{N}$. ketagalan}

A total of $27 N$. ketagalan haplotypes from 126 sequences were defined by 44 variable sites and 36 phylogenetically informative sites. The nucleotide sequences were $\mathrm{A}+\mathrm{T}$ rich (58.2\%). The mean COI haplotype diversity in each population was 0.49 (range: 0.00 to 0.75 ) (Table 1). The estimates of $\theta_{\pi}$ and $\theta_{\omega}$ indicated that this species showed a pattern of decline $\left(\theta_{\pi}<\theta_{\omega}\right)$ (Table 1$)$. A comparison of the fixation indices $N_{\mathrm{ST}}$ and $G_{\mathrm{ST}}$ revealed that $N_{\mathrm{ST}}$ was larger than $G_{\mathrm{ST}}(0.82$ and 0.44 , respectively; Table 3). This result suggested a weak relationship between phylogeny and geography.

Table 3 Results of the dynamic tests and molecular clock analyses for the Neocaridina species in Taiwan.

\begin{tabular}{|c|c|c|c|c|c|c|c|}
\hline Species & Tajima's D & Fu's Fs & SSD & $\mathrm{Rg}$ & $T_{\text {MRCA }}$ & $N_{S T}$ & $G_{S T}$ \\
\hline \multirow[t]{2}{*}{ N. davidi } & $-1.443(>0.10)$ & $-17.477(0.000)$ & $0.005(0.840)$ & $0.007(0.950)$ & $0.242(0.125-0.374)$ & 0.72 & 0.47 \\
\hline & & & & & $0.532(0.275-0.844)$ & & \\
\hline \multirow[t]{2}{*}{ N. ketagalan } & $-0.727(>0.10)$ & $-3.281(0.016)$ & $0.004(0.430)$ & $0.014(0.300)$ & $0.370(0.202-0.560)$ & 0.82 & 0.44 \\
\hline & & & & & $0.774(0.415-1.176)$ & & \\
\hline \multirow[t]{2}{*}{ N. saccam } & $1.370(>0.10)$ & $4.327(0.022)$ & $0.092(0.070)$ & $0.099(0.120)$ & $0.432(0.176-0.727)$ & 0.95 & 0.58 \\
\hline & & & & & $0.938(0.378-1.610)$ & & \\
\hline \multirow[t]{2}{*}{ N. sp. } & $-2.414(<0.01)$ & $1.092(0.181)$ & $0.021(0.060)$ & $0.158(0.020)$ & $1.021(0.537-1.591)$ & 0.28 & 0.51 \\
\hline & & & & & $2.180(1.163-3.449)$ & & \\
\hline
\end{tabular}

The Tajima's D, Fu's $F_{\mathrm{S}}$ and mismatch distributions indices (i.e., sum of squared deviations from the sudden expansion model, SSD, and raggedness index, Rg) are reported. The corresponding $P$-values are given in brackets 

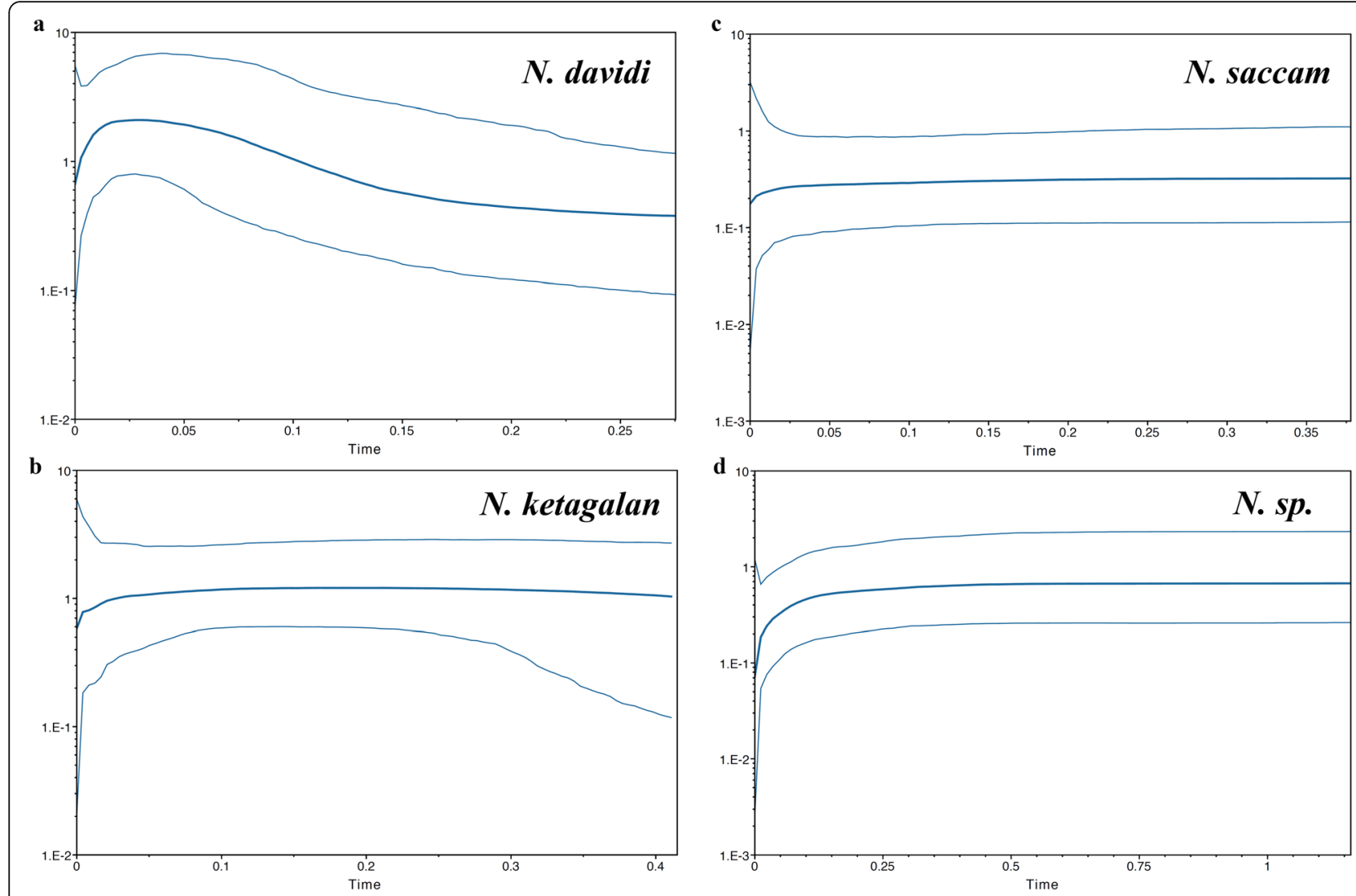

Fig. 4 Bayesian skyline plot of the effective population sizes over time for N. davidi a, N. ketagalan b, N. saccam c and N. sp. d in Taiwan

Among the 27 haplotypes, four haplotypes (K1-K4) were shared between two or more populations (Table 1). Among these ten sampling populations, two populations (XH and DA) had two shared haplotypes, and four populations (ML, DT, LZ and JG) did not have any shared haplotypes. The haplotype trees reconstructed with different methods (ML and $\mathrm{BI}$ ) were identical. In the BI tree (Fig. 5b), $27 \mathrm{mtDNA}$ haplotypes fell into three lineages (NK1-NK3). Lineage NK1 included three populations in northern Taiwan; lineage NK2 contained seven populations in northern and central Taiwan; lineage NK3 only contained one population (DS) in northern Taiwan (Fig. 5b). To detect the ancestral region, all sampling populations were sorted into three regions, A1, A2, and B (Fig. 5b). Northern Taiwan (A) was divided into two sub-regions (A1 and A2) by the Taoyuan Plateau (Fig. 1). The results of the S-DIVA analysis produced a scenario with vicariance and dispersal events that shaped the current distribution patterns (Fig. 5b). The ancestral populations of $N$. ketagalan were distributed north of the Taoyuan Plateau and then dispersed southward.

\section{Population diversity of $N$. saccam and $N$. species in eastern Taiwan}

A total of eight $N$. saccam COI haplotypes from 47 sequences were defined by 17 variable sites and 15 phylogenetically informative sites. The nucleotide sequences were $\mathrm{A}+\mathrm{T}$ rich (58.7\%). The mean COI haplotype diversity in each population was 0.17 (range: 0.00 to 0.68 ) (Table 1). The haplotype and nucleotide diversities in most populations were 0.00 . This result revealed very high levels of differentiation among the populations. A comparison of the fixation indices $N_{\mathrm{ST}}$ $(0.95)$ and $G_{\text {ST }}(0.58)$ revealed a weak relationship between phylogeny and geography (Table 3 ). Among the eight haplotypes, three haplotypes (S1-S3) were shared between two adjacent populations (Table 1). The haplotype trees reconstructed with different methods (ML and $\mathrm{BI}$ ) were identical. In the BI tree (Fig. 5c), all haplotypes fell into two lineages (NS1 and NS2). Lineage NS1 included four populations south of the Formosa Bank, and lineage NS2 contained two populations north of the Formosa Bank (Figs. 1 and 5c). The results of the S-DIVA analysis showed that the ancestral populations of $N$. saccam were distributed in north- (C1) and south (C2) of Formosa Bank (Figs. 1 and 5c).

The six haplotypes from the 43 sequences of $N$. sp. in eastern Taiwan were defined by 30 variable sites and 6 phylogenetically informative sites. The nucleotide sequences were $\mathrm{A}+\mathrm{T}$ rich (59.1\%). The mean haplotype diversity in each population was 0.30 (range: 0.00 to 

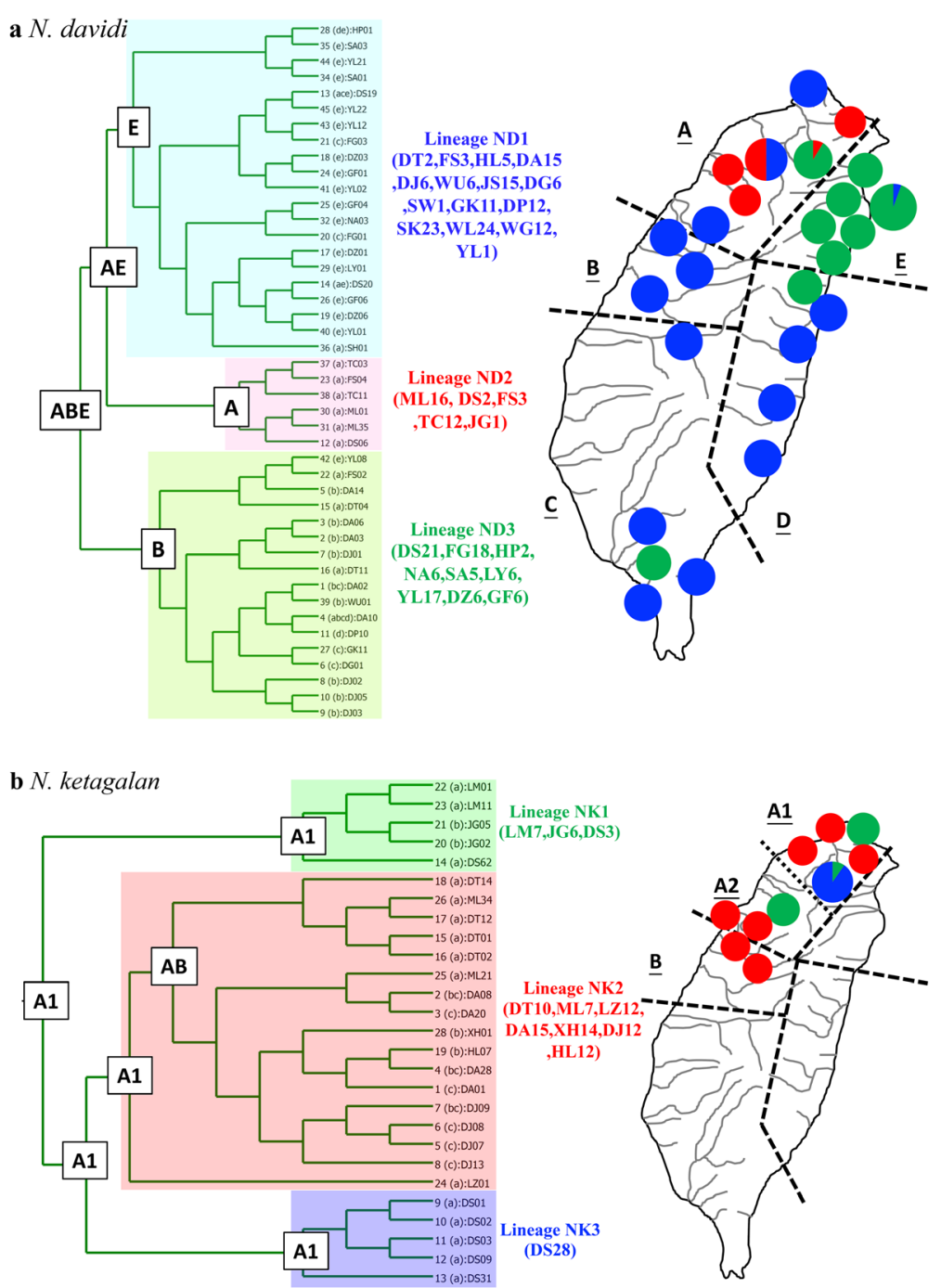

c N. saccam

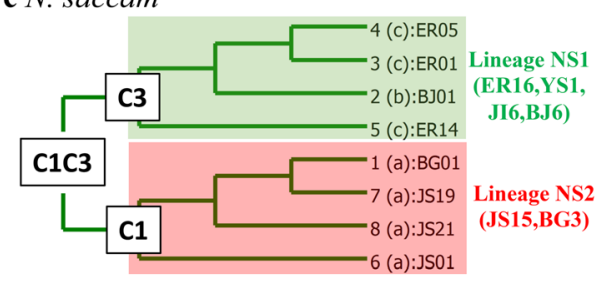

d $N . s p$.
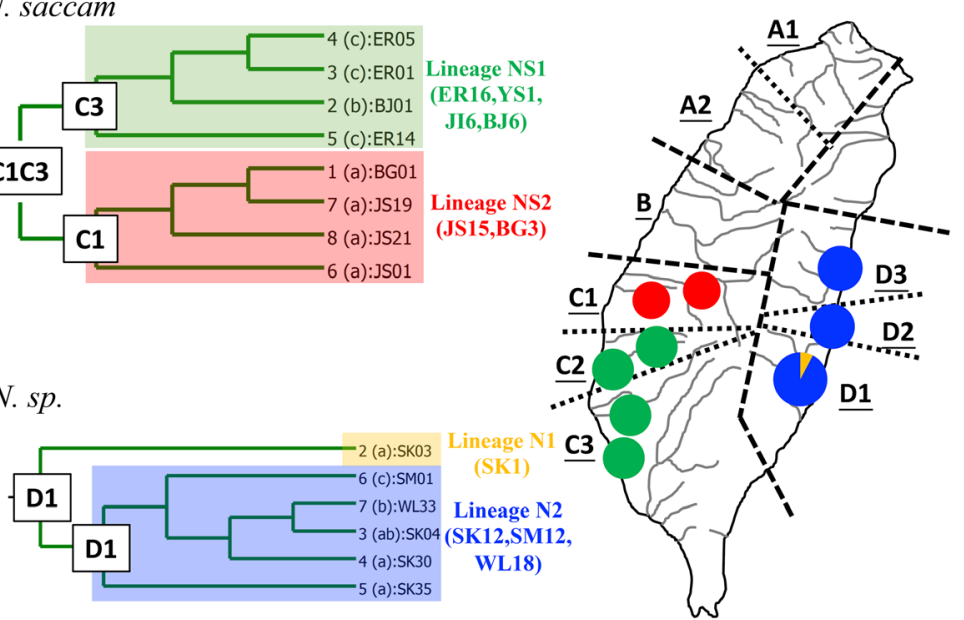

Fig. 5 BEAST-derived chronograms of the mitochondrial DNA haplotypes of the Neocaridina davidi a, N. ketagalan $\mathbf{b}, N$. saccam c and Neocaridina sp. $\mathbf{d}$ in Taiwan. The numbers at the nodes are the bootstrap values (maximum likelihood). The ancestral distribution inferred using S-DIVA is given in the box above each node. The frequencies of the lineages in each population and the range information are displayed on map 
0.53) (Table 1). A comparison of the fixation indices $N_{\mathrm{ST}}$ $(0.28)$ and $G_{\mathrm{ST}}(0.51)$ displayed that the most related haplotypes were found in different populations (Table 3 ). Compared with those of other species, the $N_{\mathrm{ST}}$ of $N$. sp. was the smallest (Table 3). These results suggested that the level of population differentiation of $N$. sp. was much lower than that of the other three species. The phylogenetic analyses also revealed mixed populations (Fig. 5d). The results of the S-DIVA analysis indicated that the ancestral population was distributed in the population SK and then to the north.

\section{Discussion}

\section{Systematics of the genus Neocaridina}

Many studies suggest that species should fulfil two criteria, monophyly and distinctness [33-35]. In the present study, the freshwater shrimp Neocaridina in Taiwan formed four monophyletic clades (clades 1, 6, 9 and 12; Fig. 2), and the mean genetic distance among these four clades was $6.64 \%$ (ranging 5.74 to $7.50 \%$; Table 2). The range of the pairwise genetic distance between these 13 clades of Neocaridina (Fig. 2) was from $2.87 \%$ (between $N$. davidi and $N$. denticulata) to $15.23 \%$ (between $N$. sp. in Japan and N. spinose), and the average pairwise distance was $8.19 \%$ (Table 2). Robe et al. [29] evaluated the utility of mtDNA COI in the identification of species of Palaemonidae (Crustacea, Decapoda) and found that the mean genetic distances between the species within the genus Macrobrachium ranged from 0.000 to 0.312 (mean $=0.198$ ). Hebert et al. [36] suggested that the best threshold for distinguishing intra- from interspecific divergence was approximately $3 \%$ sequence divergence, although this value was later modified approximately ten times by many studies [37-40]. Thus, the present study suggested that the four clades in Taiwan corresponded to four species: N. davidi, N. saccam, $N$. ketagalan and one undescribed species $(N$. sp. in Taiwan) (Fig. 2; Table 2). Our study provides a table comparing the morphologic characteristics among these four Neocaridina species in Taiwan and their identification keys (Table 4).

Recently, Shih et al. [41] proposed the third endemic species of Neocaridina known from Taiwan. This new species of land-locked freshwater shrimp, N. fonticulata, is described from Kenting, Hengchun Peninsula, and southern Taiwan [41]. However, although our study sampled specimens from 35 localities in Taiwan, which covers almost all rivers within the island, we did

Table 4 Comparison of the morphological characters among four Neocaridina species in Taiwan and their identification keys

\begin{tabular}{|c|c|c|c|c|}
\hline & N. davidi & N. saccam & N. ketagalan & N. sp. \\
\hline 1. The merus of the 1st pereiopod (as long as wide) & 2.5 & $1.4-1.7$ & $1.8-2.2$ & $1.8-2.0$ \\
\hline $\begin{array}{l}\text { 2. The carpus of the } 1 \text { st pereiopod in the male } \\
\text { (as long as high) }\end{array}$ & 1.7 & 1.4 & 1.6 & $1.2-1.5$ \\
\hline $\begin{array}{l}\text { 3. The number of accessory spines on the dactylus } \\
\text { of the } 3 \text { rd pereiopod }\end{array}$ & $5-8$ & $4-6$ & $4-6$ & $4-6$ \\
\hline 4. Endopod of the male 1st pleopod (as long as wide) & 1.2 & 1.4 & 1.4 & 1.7 \\
\hline 5. Propodus of the 3rd pereiopod (as long as dactylus) & 3.0 & $2.7-3.2$ & $3.5-3.9$ & $2.7-3.0$ \\
\hline 6. Dactylus of the 5th pereiopod (as long as broad) & & $3.0-3.5$ & $3.7-4.0$ & $2.9-3.4$ \\
\hline 7. The number of spinules on the uropodal diaeresis & $9-13$ & $12-14$ & $14-17$ & $13-14$ \\
\hline \multicolumn{5}{|l|}{ Keys to Taiwan species of the Neocaridina group: } \\
\hline $\begin{array}{l}\text { 1a. Rostrum reaching slightly beyond the end of the } \\
\text { 1st segment of the antennular peduncle, endopod } \\
\text { of the male } 1 \text { st pleopod } 1.7 \text { times as long as wide }\end{array}$ & & & & N. sp. \\
\hline $\begin{array}{l}\text { 1b. Rostrum reaching or more than the mid-length } \\
\text { of the } 2 \text { nd of antennular peduncle, endopod of the } \\
\text { male } 1 \text { st pleopod less than } 1.7 \text { times as long as wide }\end{array}$ & & & & 2 \\
\hline $\begin{array}{l}\text { 2a. Carpus of 1st pereiopod in the male more than } \\
1.6 \text { times as long as high }\end{array}$ & & & & 3 \\
\hline $\begin{array}{l}\text { 2b. Carpus of first pereiopod in the male } 1.4 \text { times } \\
\text { as long as high }\end{array}$ & & & & N. saccam \\
\hline $\begin{array}{l}\text { 3a. Propodus of the } 3 \text { rd pereiopod more than } 3.5 \\
\text { times as long as dactylus, pleopod } 1.3-1.5 \text { times as } \\
\text { long as wide, endopod of the male } 1 \text { st pleopod less } \\
\text { than } 1.4 \text { times as long as wide }\end{array}$ & & & & N. ketagalan \\
\hline $\begin{array}{l}\text { 3b. Propodus of the } 3 \text { rd pereiopod less than } 3.5 \text { times } \\
\text { as long as dactylus, endopod of the male } 1 \text { st pleopod } \\
\text { less than } 1.2 \text { times as long as wide }\end{array}$ & & & & N. davidi \\
\hline
\end{tabular}


not sample any specimens in the Hengchun Peninsula (Fig. 1). After comparing the morphological characteristics (Table 4 and Shih et al. [41]), our study found that $N$. sp. in Taiwan may be synonymous with $N$. fonticulata. However, the molecular data of $N$. fonticulata have not been released. Therefore, this question needs to be confirmed in the future.

Moreover, our study found that the systematics of $N$. davidi were unclear. Neocaridina davidi, once named $N$. denticulate sinensis [5], and Shih et al. [2] suggested that it was synonymous with $N$. davidi. However, our study found that the genetic distance between $N$. davidi and $N$. denticulata was the smallest (2.87\%). Thus, we could not suggest that "N. davidi in Taiwan" was a species, subspecies or population. The systematics and distribution area of $N$. denticulata were also unclear. Moreover, our study also found that there were many questions about the systematics of the genus Neocaridina in East Asia. For example, clade 11 (name: Nak; accession no. LC324777) was named $N$. aff. Koreana [2], but it is not close to N. koreana (clade 3; Fig. 2) (name: Nkr; accession no. LC324768 in Shih et al. [2]). Furthermore, undescribed Neocaridina species were found not only in our study (Fig. 2; clade 4, N. sp. in China, and clade 9, $N$. sp. in Taiwan) but also in the study of Shih et al. [2] (clade 10, $N$. sp. in Japan). Our study suggests that the systematics and species diversity of the genus Neocaridina in East Asia need revisions in future studies.

As described above, the diversity of the genus Neocaridina is outside of our understanding. The distribution of the shared haplotypes (Table 1) and $N_{\mathrm{ST}}$ (Table 3) within each species showed high population differentiation. These results suggested weak migrating potential in the Neocaridina species. Thus, their distribution patterns were restricted (Fig. 2), and the ancestral populations were easily isolated. These results were also supported by the DIYABC analysis (Fig. 3). The four species did not colonize Taiwan by one colonization route (scenario E, Fig. 3e) because the ancestral populations could not disperse over the entire island. Thus, these four Neocaridina species in Taiwan may have colonized the islands through four different groups of ancestral populations.

\section{Multiple origins of the genus Neocaridina in Taiwan}

Our study found four Neocaridina species in Taiwan. The distribution ranges of the three species, $N$. saccam, N. ketagalan and $N$. sp., were restricted, and only $N$. davidi was widely distributed (Fig. 2). The phylogenetic analysis of Neocaridina species in the world revealed that these four species in Taiwan were polytomous (Fig. 2). The $\mathrm{T}_{\mathrm{MRCA}}$ of these four Taiwanese species were different (Table 3). Moreover, the results of the DIYABC analysis demonstrated that these four Neocaridina species colonized Taiwan during four colonization events (Fig. 3). Chang et al. [19] also found that two endemic Microphysogobio species colonized Taiwan from two origins and through two colonization centres. Previous studies $[9,19,42]$ propose that due to the geological history of Taiwan Island, the different colonization times shaped the different distribution patterns. These present results of the genus Neocaridina in Taiwan agreed with those of previous studies $[9,19,42]$. The four Neocaridina species in Taiwan displayed different distribution patterns, and they may have colonized the islands at different times.

Many studies $[9,18,19,42]$ have suggested that when the freshwater species colonized Taiwan after the island reached its present shape, their distribution range was restricted. Among the four species in Taiwan, $N$. sp. was restricted to eastern Taiwan. However, the distribution patterns of the freshwater fishes and the phylogeographic studies $[10,19]$ indicate that the Central Range has acted as a barrier to dispersal between the western and eastern populations of species. Thus, many freshwater species were not distributed in eastern Taiwan, and some species were distributed in eastern Taiwan by human activities [26]. Thus, the freshwater species in eastern Taiwan colonized before those in western Taiwan or originated from populations in western Taiwan through human activities. The results of $\mathrm{T}_{\text {MRCA }}$ estimated that $N$. sp. colonized before other species (Table 3). Based on the substitution rate of $1.1 \%$ per million years [31], the $\mathrm{T}_{\mathrm{MRCA}}$ of $N$. sp. was 2.180 mya, which was before the Central Range in Taiwan formed (ca. 2 mya). In addition, the results of the DIYABC analysis also supported that the genus Neocaridina colonized Taiwan through four colonization events. Thus, this study suggested that $N$. sp. colonized Taiwan before the island reached its current shape, and the $\mathrm{T}_{\mathrm{MRCA}}$ based on the substitution rate of $1.1 \%$ per million years was likely an appropriate estimate.

According to previous studies $[9,17,18,20,26]$, the freshwater species colonized Taiwan through five colonization centres: two to the south of the Formosa Bank, two to the north of the Formosa Bank and the south of the Miaoli Plateau, and one to the north of the Miaoli Plateau. In the phylogeny of the genus Neocaridina (Fig. 2), N. ketagalan was grouped with $N$. aff. Koreana and N. sp. in Japan as monophyletic. The pairwise p-distance between the clades of Neocaridina suggested that $N$. ketagalan was close to $N$. aff. Koreana in Japan (Table 2). Moreover, the S-DIVA analyses showed that the ancestral populations of $N$. ketagalan were distributed north of the Taoyuan Plateau (Fig. 5b). Our study found that M. brevirostris and $N$. ketagalan had the same distribution area, but Chang et al. [19] proposed that $M$. brevirostris might have originated from mainland China. However, in a 
study by Chang et al. [19], we found that M. brevirostris was close to M. koreensis from South Korea. Moreover, Chiu et al. [18] found that the freshwater snail in northern Taiwan originated from Japan. Thus, this study considered that the freshwater species in northern Taiwan might not have colonized from mainland China and suggested that $N$. ketagalan originated from Japan (Fig. 1).

Neocaridina saccam was only distributed south of the Miaoli Plateau, and the results of the S-DIVA analysis demonstrated that the ancestral populations of $N$. saccam were distributed south and north of the Formosa Bank (Figs. 1 and 5c). Based on these results, N. saccam did not colonize Japan. According to the geographic locations, our study suggested that $N$. saccam originated from mainland China (Fig. 1). Actually, this colonization route was the most common to Taiwan Island [17, 23, 32, 43]. In addition, our study found that $N$. sp. in eastern Taiwan may be synonymous with $N$. fonticulata in the Hengchun Peninsula (Fig. 1). If this hypothesis is supported, N. sp. was also distributed in southern Taiwan. This distribution pattern was similar to that of two freshwater fishes, Spinibarbus hollandi and Onychostoma alticorpus. Chiang et al. [20] proposed that these two fishes colonized the island in the southern region of the Kaoping foreland basins, followed by eastern and northward dispersal. Thus, our study considered that $N$. sp. in Taiwan (N. fonticulata) may have colonized mainland China (Fig. 1).

In addition, although the S-DIVA analyses showed that the ancestral populations of $N$. davidi were distributed in northern Taiwan, this species is widely distributed around the world. Moreover, the phylogenetic analysis showed that $N$. davidi was close to $N$. denticulata in Japan. Neocaridina davidi may have colonized Japan (Fig. 1). However, our study could not suggest a geographical origin because the systematic status of this species was unidentified. Accordingly, this study suggested that the Neocaridina species in Taiwan colonized the area from multiple geographical and temporal origins, but the deterministic geographical sources need further study.

\section{Population history of $\mathbf{N}$. sp. in eastern Taiwan}

Our study found that $N$. sp. was distributed only in three adjacent rivers: SK, SM and WL (Figs. 2 and 5d). Although the $N_{\mathrm{ST}}$ in this species was smaller than those in other species, only this species displayed a higher $G_{\text {ST }}$ than $N_{\mathrm{ST}}$ (Table 3). These results suggested that most related haplotypes were found in different populations. However, the depth of the sea around eastern Taiwan was deeper than the depth in western Taiwan (Taiwan Strait), and even during the glaciations, these oceans around eastern Taiwan were not exposed. Previous studies have demonstrated that the amphidromous fish $R$. giurinus [43] and shrimp Caridina pseudodenticulata [42] larvae survived in seawater and could not cross this deep sea. How did $N$. sp. colonize or migrate among these three rivers? The geological study of Taiwan Island [44] proposed that these three adjacent rivers belonged to one river, the paleo-Siuguluan River (paleo-SK), and separated after the middle Pleistocene.

\section{Phylogeography of $N$. saccam and N. ketagalan}

Neocaridina saccam were divided into two lineages, NS1 and NS2 (Fig. 5c), and exhibited a southern and northern distribution, which were to the south and to the north of the Formosa Bank. The S-DIVA analysis showed that the ancestral populations of $N$. saccam were distributed to the south and north of Formosa Bank (Fig. 5c). Moreover, only two populations, JS, the northernmost population, and ER, the southernmost population, had private haplotypes (Table 1; Fig. 1). These results seemed to reveal that the colonization route was divided into two routes by the Formosa Bank. The Formosa Bank is located in the southern part of the Taiwan Strait. Previous studies $[9,17,19,45]$ have suggested that the Formosa Bank divided the glacial land bridge in the Taiwan Strait; however, the role of the Formosa Bank on the population dispersion within the island was rarely described. Ju et al. [26] proposed that during the maximum glacial periods, the ridge lifted from Formosa Bank to the present coastline of Taiwan Island. Therefore, during the maximum glaciation, the dispersal between the two sides of the bank through the exposed continental shelves of the island were prevented. After N. saccam colonized the island, the northward dispersal route was interrupted by the Miaoli Plateau, and the southward dispersal route was fragmented by the Kaoping foreland basins (Fig. 1).

Neocaridina ketagalan can be divided into three lineages (NK1-NK3, Fig. 5b). Lineage NK3 was restricted to the northern region of the Taoyuan Plateau, lineage NK1 was restricted to the north region of the Miaoli Plateau, and lineage NK2 was restricted to the north region of the Formosa Bank (Figs. 1 and 5b). The S-DIVA analysis displayed that its ancestral populations were distributed north of the Taoyuan Plateau and then southward (A1 region; Fig. 5b). Finally, the population structure was shaped by the Taoyuan Plateau, Miaoli Plateau and Formosa Bank. The Taoyuan Plateau is located in northwestern Taiwan (Fig. 1). Some freshwater fishes, e.g., O. evolans, Squalidus argentatus, Sinibrama macrops and Hemibarbus labeo, were only distributed in the Tamsui River north of the Taoyuan Plateau (excluding). Chang et al. [19] and Hsu et al. [23] also found that the Taoyuan Plateau divided the populations of M. brevirostris and Semisulcospira libertina into different lineages. Thus, the lineage NK3 was restricted to the northern region of the Taoyuan Plateau. Moreover, many studies suggest that the Miaoli Plateau prevented 
the dispersal of the freshwater fishes $[9,19]$. Thus, when the Miaoli Plateau emerged, the populations were isolated and diverged (lineage NK1). Last, as described above, during the maximum glaciation, the Formosa Bank interrupted the migrations of $N$. saccam and $N$. ketagalan.

\section{Population history of $\boldsymbol{N}$. davidi in Taiwan}

Among the four Neocaridina species in Taiwan, the distribution range of $N$. davidi was wider than those of the others (Fig. 2). According to a previous study $[9,18]$, this widely distributed species colonized Taiwan Island before the species with restricted ranges. However, the results of the $\mathrm{T}_{\text {MRCA }}$ analysis showed that $N$. davidi colonized the islands after the other species (Table 3). In addition, our study also found that this species was widely distributed throughout the world. Neocaridina davidi is known to be an invasive species due to its importance in the aquarium trade (Englund and Cai [46] for Hawaii; Jabłońska et al. [47] for Poland; Klotz et al. [48] for Germany). Thus, some populations might have resulted from introduction into the wild from aquarium stocks.

Neocaridina davidi in Taiwan can be divided into three lineages (ND-ND3, Fig. 5a). Lineage ND2 was only distributed north of the Miaoli Plateaus, lineage ND3 was mostly distributed in northeastern Taiwan, and lineage ND1 was widely distributed. The results of the S-DIVA revealed that the ancestral populations were distributed north of the Formosa Bank and in northeastern Taiwan. Moreover, our study found that some populations did not have private haplotypes, and these populations were not distributed in ancestral areas, excluding population FG (Table 1; Figs. 1 and 5a). In addition, the shared haplotypes of the other three species were only distributed in the neighbour populations, and the shared haplotypes of $N$. davidi, excluding D9 and D10, were also distributed in the neighbour populations (Table 1). Thus, we suggest that the distribution of the widespread haplotype and the discontinuous distribution might have resulted from introductions to the wild from aquarium stocks, and the human-caused transformations among the wild population were rarer than the introductions of individuals to the wild from aquarium stocks.

In conclusion, our study considered that the ancestral populations of $N$. davidi were distributed north of the Formosa Bank and in northeastern Taiwan (Fig. 5a) and then isolated and divergent by the Central Range and Miaoli Plateau. Finally, the ND1-ND3 lineages were restricted to northeastern Taiwan (E region), north of the Miaoli Plateau (A region), south of the Miaoli Plateau and north of the Formosa Bank (B region). We suggested that the populations in regions $\mathrm{C}$ and $\mathrm{D}$ might have resulted from the introduction from aquarium stocks to the wild by humans (Fig. 5a).

\section{Conclusions}

This study found that there were four Neocaridina species in Taiwan and that they originated through four colonization events. There were five phylogeographic breaks in Taiwan: the Central Range, Taoyuan Plateau, Miaoli Plateau, Formosa Bank and Kaoping foreland basins. This study found that the population sizes of these four species all displayed declines (Fig. 4). In the census programme of the Neocaridina species in Taiwan, we found that the Neocaridina species is rare or has disappeared in many rivers. Thus, the results of the present study provide information to conservation management agencies about the patterns of genetic diversity and the structure of the Neocaridina species in Taiwan. However, this study did not determine the systematics of the genus Neocaridina in East Asia. The results of the present study provide information on the phylogeography of East Asia and the history of the genus Neocaridina. In future studies, we need more sampling and more genetic characters.

\section{Methods}

\section{Population sampling and molecular methods}

A total of 479 specimens of Neocaridina species were collected from 35 localities in Taiwan, which almost covers all rivers within the island (Fig. 1; Table 1). Neocaridina species are not endangered or protected species, and the fieldwork was conducted in accordance with the guidelines established by the National Museum of Marine Biology and Aquarium in Taiwan. All specimens were stored in the laboratory of Chiao-Chuan Han, National Museum of Marine Biology and Aquarium. The shrimp were collected from field sites with seines and fatally anaesthetized with MS-222 (Sigma, St. Louis, MO). The samples were fixed and stored in 100\% ethanol. The genomic DNA was extracted from the muscle tissue using the Genomic DNA Purification Kit (Gentra Systems, Valencia, CA, USA). The partial COI gene was amplified by polymerase chain reaction (PCR) using the primers LCO1490 (5'-GGTCAA CAAATCATAAAGATATTGG-3') and HCO2198 (5'TAAACTTCAGGGTGACCAAAAAATCA-3') [49]. Each $50 \mu \mathrm{l}$ PCR mixture contained $5 \mathrm{ng}$ of template DNA, $5 \mu \mathrm{l}$ of $10 \mathrm{x}$ reaction buffer, $4 \mu \mathrm{l}$ of dNTP mix $(10 \mathrm{mM}), 5 \mathrm{pmol}$ of each primer and $2 \mathrm{U}$ of Taq polymerase (TaKaRa, Taq polymerase). The PCR was programmed on an MJ Thermal Cycler for one cycle of denaturation at $94^{\circ} \mathrm{C}$ for 3 min, 40 cycles of denaturation at $94^{\circ} \mathrm{C}$ for $30 \mathrm{~s}$, annealing at $55^{\circ} \mathrm{C}$ for $30 \mathrm{~s}$ and extension at $72^{\circ} \mathrm{C}$ for $1 \mathrm{~min} 30 \mathrm{~s}$, followed by a $72^{\circ} \mathrm{C}$ extension for $10 \mathrm{~min}$ and $4{ }^{\circ} \mathrm{C}$ for storage. The purified PCR products were sequenced using an ABI 377 automated sequencer (Applied Biosystems, Foster 
City, CA, USA). The chromatograms were checked with the CHROMAS software (Technelysium), and the sequences were manually edited using BIOEDIT 6.0.7 [50]. All new sequence data were submitted to GenBank (MG734216-MG734300). Moreover, to identify the Neocaridina species and find the origins of the genus Neocaridina in Taiwan, our study also downloaded the sequences in Shih et al. [2] from GenBank (AB300177-90 and LC324764-79). In addition, our study also sampled some specimens in the Yangtze River (population CJ) and Hanjiang River (population HJ) in mainland China (Fig. 1).

\section{Sequence alignment and phylogenetic inferences}

The nucleotide sequences were aligned in Clustal X 1.81 [51]. The selection of the best-fit nucleotide substitution models was performed using the Bayesian information criterion (BIC) in jModelTest 2.0 [52]. The most appropriate nucleotide substitution model was HKY + I + G (HasegawaKishino-Yano). The phylogenetic relationships among all haplotypes were inferred using Bayesian inference (BI) and maximum likelihood (ML) in BEAST 1.8.0 [53] and MEGA 6 [54]. For the BEAST analysis, a stick clock model with a Bayesian Skyline tree was used. We ran $10^{6}$ generations. The burn-in and plots for each analysis were visualized using Tracer v1.6 [55] to determine whether the convergence and suitable effective sample sizes were achieved for all parameters. The TREEANNOTATOR in the BEAST package was used to summarize the tree data, and the tree was viewed using FigTree v1.3 [56]. For ML analysis, bootstrapping was performed with 1000 replications. In addition, the time to the most recent common ancestor $\left(\mathrm{T}_{\text {MRCA }}\right)$ was also calculated using the software package BEAST. The substitution rates of $2.33 \%$ per million years for terrestrial Sesarma $[2,5,30]$ and $1.1 \%$ per million years for Decapoda [31] were used.

\section{Population genetic diversity}

The intra-population genetic diversity levels were estimated using haplotype diversity $(h)$ [57] and nucleotide diversity $\left(\theta_{\pi}\right.$ and $\left.\theta_{\omega}\right)$ indices [58] in DnaSP v5 [59]. The current genetic diversity estimates $\left(\theta_{\pi}\right)$ were based on the pairwise differences between the sequences, and the historical diversity estimates $\left(\theta_{\omega}\right)$ were based on the number of segregating sites among the sequences. Comparing the estimates generated by these two indices provided insight into the population dynamics over recent evolutionary history [60]. The existence of a phylogeographic structure was examined following the method of Pons and Petit [61] by calculating two genetic differentiation indices $\left(G_{\mathrm{ST}}\right.$ and $\left.N_{\mathrm{ST}}\right)$ in DnaSP.

\section{Population history}

To determine the potential diversification scenarios, a statistical dispersal-vicariance analysis (S-DIVA), which complements DIVA, was employed to determine the statistical support for the ancestral range reconstructions [62]. The tree file formats were generated using the program BEAST. The range information was defined using the ichthyofaunal classification and phylogeographic studies $[10,32]$. The analysis was performed using the 'maxareas $=2$ to 5 ' option (see RESULTS: Population diversity of Taiwan species; Fig. 5).

In addition, the demographic histories were reconstructed using three different approaches. First, we performed Tajima's D and Fu's $F_{S}$ neutrality tests $[63,64]$ in DnaSP. Under a population expansion model, the significant negative values of Tajima's $\mathrm{D}$ and Fu's $\mathrm{F}_{\mathrm{S}}$ were expected. Second, the mismatch distribution [65] was estimated under the assumption of a sudden expansion model as implemented in Arlequin version 3.5 [66]. The sum of the squared deviations (SSD) between the observed and expected mismatch distributions and the raggedness index $(\mathrm{Rg})$ were used as test statistics with the 1000 bootstrap replicates. In the third approach, we reconstructed the historical demography using the coalescent-based Bayesian skyline plot approach (BSP) implemented in software package BEAST.

To reconstruct the unknown history of divergence, we performed approximated Bayesian computations (ABC) using DIYABC v.2.0 [67]. The DIYABC program enabled the comparison of the different historical scenarios involving population divergence, admixture and population size changes and subsequently inferred the demographic and historical parameters under the best-supported scenario. The reference table was built with 1000,000 simulated data sets per scenario using the following summary statistics: one-sample statistics for the number of haplotypes, Tajima's $D$, the mean number of pairwise differences, the variance in the pairwise differences, and the number of segregating sites; two-sample statistics for the mean of the within-sample pairwise differences, the mean of the between-sample pairwise differences, the number of segregating sites and $F_{\mathrm{ST}}$ between samples. The uniform priors for all scenarios were used, and no constraints on population sizes and coalescent times were given. All the scenarios were compared using direct $(\mathrm{D})$ and logistic regression $(\mathrm{L})$ approaches, and parameter estimation was performed only for the scenarios with the highest posterior probability.

\footnotetext{
Abbreviations

ABC: Approximate Bayesian Computations; BI: Bayesian inference:

COI: Cytochrome c oxidase subunit I; ML tree: Maximum- Likelihood tree; Rg index: the raggedness index; S-DIVA analysis: Statistical Dispersal-Vicariance Analysis; SSD: the sum of square deviations
}

Acknowledgements

We thank Prof. Po-Hsun Kuo, Department of Industrial Management, National Taiwan University of Science and Technology, Taipei, Taiwan, for part of the data analysis. 


\section{Authors' contributions}

CCH, LSF and IMC took part in fieldwork and performed molecular analyses $\mathrm{CCH}, \mathrm{CCH}, \mathrm{KCH}$ and $\mathrm{HDL}$ interpreted the data, and drafted the manuscript. LSF and IMC designed the research, took part in some field works, polished the manuscript. All authors discussed the results, read and approved the final version of the manuscript for publishing.

\section{Funding}

This work was supported by grants from the National Museum of Marine Biology and Aquarium and the Taiwan's Forestry Bureau. The funding source had no role in the study design, collection, analysis and interpretation of data, writing the manuscript, or decision to submit results.

\section{Availability of data and materials}

All mtDNA sequences generated in this study have been deposited in GenBank under accession numbers: MG734216-MG734300.

\section{Ethics approval and consent to participate}

Ethical approval for this study was conducted in accordance with guidelines established by the National Museum of Marine Biology and Aquarium in Taiwan. No endangered or protected species were involved.

\section{Consent for publication}

Not applicable.

\section{Competing interests}

The authors declare no competing interests in the preparation and execution of this manuscript. The authors are solely responsible for its content.

\section{Author details \\ ${ }^{1}$ National Museum of Marine Biology and Aquarium, Pingtung 944, Taiwan. ${ }^{2}$ Graduate Institute of Marine Biology, National Dong Hwa University, Pingtung 944, Taiwan. ${ }^{3}$ College of Fisheries, Guangdong Ocean University, Zhanjiang 524088, China. ${ }^{4}$ Center for Environmental Toxin and Emerging-Contaminant Research,Cheng Shiu University, Kaohsiung 83347, Taiwan. ${ }^{5}$ Department of Leisure and Sport Management, Cheng Shiu University, Kaohsiung 83347, Taiwan. ${ }^{6}$ Department of Marine Biotechnology and Resources, National Sun Yat-sen University, Kaohsiung 80424, Taiwan. ${ }^{7}$ The Affiliated School of National Tainan First Senior High School, Tainan 701, Taiwan.}

\section{Received: 7 July 2019 Accepted: 31 October 2019}

\section{Published online: 21 November 2019}

\section{References}

1. Liang XQ. Fauna Sinica. Invertebrata: Crustacea: Decapoda: Atyidae. Beijing: Science Press; 2004. (In Chinese)

2. Shih HT, Cai Y, Niwa N, Nakahara Y. A new species of land-locked freshwater shrimp of the genus Neocaridina (Decapoda: Caridea: Atyidae) from Iki Island, Kyushu. Japan Zool Stud. 2017:56:30.

3. Hung MS, Chan TY, Yu HP. Atyid shrimps (Decapoda: Caridea) of Taiwan, with descriptions of three new species. J Crustacean Biol. 1993; 13(3):481-503

4. Shy JY, Yu HP. Freshwater shrimps of Taiwan. National Museum of Marine Biology/Aquarium: Kaohsiung, Taiwan; 1998. (In Chinese)

5. Shih HT, Cai Y. Two new species of land-locked freshwater shrimp genus Neocaridina Kubo, 1938 (Decapoda: Caridea: Atyidae) from Taiwan, with notes on the speciation within Taiwan Island. Zool Stud. 2007;46(6):680-94.

6. Teng LS. Geotectonic evolution of late Cenozoic arc continent collision in Taiwan. Tectonophysics. 1990;183(1-4):57-76.

7. Huang CY, Yuan PB, Song SR, Lin CW, Wang CS, Chen MT, Shyu CT, Karp B. Tectonics of short-lived intra-arc basins in the arc-continent collision terrane of the coastal range, eastern Taiwan. Tectonics. 1995;14(1):19-38.

8. Chiang TY, Lin HD, Zhao J, Kuo PH, Lee TW, Hsu KC. Diverse processes shape deep phylogeographical divergence in Cobitis sinensis (Teleostei: Cobitidae) in East Asia. J Zool Syst Evol Res. 2013;51(4):316-26.

9. Lin HD, Kuo PH, Wang WK, Chiu YW, Ju YM, Lin FJ, Hsu KC. Speciation and differentiation of the genus Opsariichthys (Teleostei: Cyprinidae) in East Asia. Biochem Syst Ecol. 2016;68:92-100.
10. Tzeng CS. Distribution of freshwater fishes of Taiwan. J Taiwan Mus. 1986:39:127-46.

11. Fairbanks RG. A 17,000-year glacio-eustatic sea level record: influence of glacial melting rates on the younger Dryas event and deep-ocean circulation. Nature. 1989;342(6250):637-42.

12. Gascoyne M, Benjamin GJ, Schwarcz HP, Ford DC. Sea level lowering during the Illinoian glaciation: evidence from a Bahama 'blue bole'. Nature. 1979; 205(4408):806-8.

13. Kimura M. Paleography of the Ryukyu Islands Tropics 2000;10:5-24.

14. Ota H. Geographic patterns of endemism and speciation in amphibians and reptiles of the Ryukyu archipelago, Japan, with special reference to their paleogeographical implications. Res Popul Ecol. 1998;40(2):189e204.

15. Chiang TY, Schaal BA. Phylogeography of plants in Taiwan and the Ryukyu archipelago. Taxon. 2006;55:31-41.

16. Qiu Y, Li L, Chen CTA, Guo XG, Jing CS. Currents in the Taiwan Strait as observed by surface drifters. J Oceanogr. 2011;67(4):395-1404

17. Chiang TY, Lin HD, Shao KT, Hsu KC. Multiple factors have shaped the phylogeography of Chinese spiny loach (Cobitis sinensis) in Taiwan as inferred from mitochondrial DNA variation. J Fish Biol. 2010;76:1173-89.

18. Chiu YW, Bor H, Kuo PH, Hsu KC, Tan MS, Wang WK, Lin HD. Origins of Semisulcospira libertina (gastropoda: semisulcospiridae) in Taiwan. Mitochondrial DNA Part A. 2017;28:518-25.

19. Chang HY, Wang WK, Chen KN, Su JK, Hsin CY, Li J, Wang YK, Lin HD. Phylogeography and genetic structure of the endemic cyprinid fish Microphysogobio brevirostris in northern Taiwan. Biochem Syst Ecol. 2016:65:176-84

20. Chiang TY, Chen YY, Lee TW, Hsu KC, Lin FJ, Wang WK, Lin HD. Comparative phylogeography of two codistributed endemic cyprinids in southeastern Taiwan. Biochem Syst Ecol. 2017;70:283-90.

21. Lin CC. An outline of Taiwan's quaternary geohistory with a special discussion of the relation between natural history and cultural history in Taiwan. Bull Dept Archaeol Anthropol. 1966;23:7-44.

22. Boggs S, Wang WC, Lewis FS, Chen JC. Sediment properties and water characteristics of the Taiwan shelf and slope. Acta Oceanogr Taiwan. 1979; 10:10-49.

23. Hsu KC, Bor H, Lin HD, Kuo PH, Tan MS, Chiu YW. Mitochondrial DNA phylogeography of Semisulcospira libertine (Gastropoda: Cerithioidea: Pleuroceridae): implications the history of landform changes in Taiwan. Mol Biol Rep. 2014;41(6):3733-43.

24. Wang HY, Tsai MP, Yu MJ, Lee SC. Influence of glaciation on divergence patterns of the endemic minnow, Zacco pachycaphalus, in Taiwan. Mole Ecol. 1999:8(11):1879-88.

25. Wang CF, Hsieh CH, Lee SC, Wang HY. Systematics and Phylogeography of the Taiwanese endemic minnow Candidia barbartus (Pisces: Cyprinidae) based on DNA sequence, allozymic, and morphological analyses. Zool J Linnean Soc. 2011;161(3):613-32.

26. Ju YM, Hsu KC, Yang JQ, Wu JH, Li S, Wang WK, Ding F, Li J, Lin HD Mitochondrial diversity and phylogeography of Acrossocheilus paradoxus (Teleostei: Cyprinidae). Mitochondrial DNA Part A. 2018;29(8):1194-202.

27. Cornils A, Wend-Heckmann B, Held C. Global phylogeography of Oithona similis s.l. (Crustacea, Copepoda, Oithonidae) - a cosmopolitan plankton species or a complex of cryptic lineages? Mol Phylogenetics Evol. 2017:107:473-85.

28. Mirimin L, Kitchin N, Impson DN, Clark PF, Richard J, Daniels SR, RoodtWilding R. Genetic and morphological characterization of freshwater shrimps (Caridina africana Kingsley, 1882) reveals the presence of alien shrimps in the cape floristic region. South Africa J Hered. 2015;106(6):711-8.

29. Robe LJ, Machado S, Bartholomei-Santos ML. The DNA barcoding and the caveats with respect to its application to some species of Palaemonidae (Crustacea, Decapoda). Zool Sci. 2012:29(10):714-24.

30. Schubart CD, Diesel $R$, Hedges SB. Rapid evolution to terrestrial life in Jamaican crabs. Nature. 1998:393(6683):363-5.

31. Bernardes SC, Pepat AR, Rintelen von T, Rintelen von K, Page TJ, Freitage $H$, de Bruyn M. The complex evolutionary history and Phylogeography of Caridina typus (Crustacea: Decapoda): long-distance dispersal and cryptic allopatric species. Sci Rep. 2017;7(1):9044.

32. Wang JP, Lin HD, Huang S, Pan CH, Chen XL, Chiang TY. Phylogeography of Varicorhinus barbatulus (Cyprinidae) in Taiwan based on nucleotide variation of mtDNA and allozymes. Mol Phylogenetics Evol. 2004;31(3):1143-56.

33. Cracraft J. Speciation and its ontology: the empirical consequences of alternative species concepts for understanding patterns and processes of 
differentiation. In: Otte D, Endler JA, editors. Speciation and its consequences. Sunderland: Sinauer Associates; 1989. p. 28-59.

34. Gill FB, Slikas B, Sheldon FH. Phylogeny of titmice (Paridae): II. Species relationships based on sequences of the mitochondrial cytochrome-b gene. Auk. 2005;122(1):121-43.

35. Wiley EO. The evolutionary species concept reconsidered. Syst Zool. 1978; 27(1):17-26

36. Hebert PDN, Cywinska A, Ball SL, deWaard JR. biological identifications through DNA barcodes. Proc. Royal Soc. B. 2003;270(1512):313-21.

37. Davison A, Blackie RLE, Scothern GP. DNA barcoding of stylommatophoran land snails: a test of existing sequences. Mol Ecol Resour. 2009;9(4):1092-101.

38. Hebert PDN, Stoeckle MY, Zemlak TS, Francis CM. Identification of birds through DNA barcodes. PLoS Biol. 2004;2(10):1657-63.

39. Lefébure T, Douady CJ, Gouy M, Gibert J. Relationship between morphological taxonomy and molecular divergence within Crustacea: proposal of a molecular threshold to help species delimitation. Mol Phylogenetics Evol. 2006:40(2):435-47.

40. Meier R, Shiyang K, Vaidya G, Ng PKL. DNA barcoding and taxonomy in Diptera: a tale of high intraspecific variability and low identification success. Syst Biol. 2006;55(5):715-28.

41. Shih HT, Cai Y, Chiu YW. Neocaridina fonticulata, a new land-locked freshwater shrimp from Hengchun peninsula, Taiwan (Decapoda, Caridea, Atyidae). ZooKeys. 2019;817:11-2

42. Han CH, Fang LS, Chang IM, Lin HD. Genetic variation of the land-locked freshwater shrimp Caridina pseudodenticulata (Decapoda: Atyidae: Caridina) in Taiwan. Mitochondrial DNA Part A. 2017;29(5):687-94.

43. Ju YM, Wu JH, Kuo PH, Hsu KC, Wang WK, Lin FJ, Lin HD. Mitochondrial genetic diversity of Rhinogobius giurinus (Teleostei: Gobiidae) in East Asia. Biochem Syst Ecol. 2016;69:60-6.

44. Hsu TL, Chen PY. On the river capture of Hualienchi. Bull Geol Surv Taiwan. 1951;3:19-21.

45. Oshima M. Studies on the distribution of the fresh-water fishes of Taiwan and discuss the geographical relationship of the Taiwan Island and the adjacent area. Zool Mag. 1923:35:1-49 (In Japanese).

46. Englund RA, Cai Y. The occurrence and description of Neocaridina denticulate sinensis. Bishop Mus Occas pap. 1999:58:58-65.

47. Jabłońska A, Mamos T, Gruszka P, Szlauer-Łukaszewska A, Grabowski M. First record and DNA barcodes of the aquarium shrimp, Neocaridina davidi, in Central Europe from thermally polluted River Oder canal, Poland. Knowl Manag Aquat Ecosyst. 2018;419:14.

48. Klota W, Miesen FW, Hüllen S, Herser F. Two Asian fresh water shrimp species found in a thermally polluted stream system in North RhineWestphalia. Germany Aquat Invasions. 2013;8(3):333-9.

49. Folmer O, Black M, Hoeh W, Lutz R, Vrijenhoek R. DNA primers for amplification of mitochondrial cytochrome c oxidase subunit I from diverse metazoan invertebrates. Mol Mar Biol Biotechnol. 1994;3(5):294-9.

50. Hall TA. BioEdit: a user-friendly biological sequence alignment editor and analysis program for windows 95/98/NT. Nucleic Acids Symp Ser. 1999;41:95-8.

51. Thompson JD, Gibson TJ, Plewniak F, Jeanmougin F, Higgins DG. The Clustal X windows interface: flexible strategies for multiple sequence alignment aided by quality analysis tools. Nucleic Acids Res. 1997;25(24): 4876-82.

52. Darriba D, Taboada GL, Doallo R, Posada D. jModelTest 2: more models, new heuristics and parallel computing. Nat Methods. 2012;9(8):772.

53. Drummond AJ, Rambaut A, Suchard M. BEAST 1.8.0. http://beast.bio.ed.ac.uk.

54. Tamura K, Stecher G, Peterson D, Filipski A, Kumar S. MEGA6: molecular evolutionary genetics analysis version 6.0. Mol Biol Evol. 2013;30:2725-9.

55. Rambaut A, Drummond AJ, Suchard M. Tracer v1.6. http://tree.bio.ed.ac.uk/ software/tracer/. Accessed 11 Dec; 2013.

56. Rambaut A. FigTree 1.3. Available at: http://tree.bio.ed.ac.uk/software/ figtree/; 2014.

57. Nei M, Tajima F. Maximum likelihood estimation of the number of nucleotide substitutions from restriction sites data. Genetics. 1983:105(1):207-17.

58. Jukes TH, Cantor CR. Evolution of protein molecules. In: Monro HN, editor. Mammalian protein metabolism. New York, NY: Academic Press; 1969. p. 21-132.

59. Librado P, Rozas J. DnaSP v5: a software for comprehensive analysis of DNA polymorphism data. Bioinformatics. 2009;25(11):1451-2.

60. Templeton AR. The 'eve' hypothesis: a genetic critique and reanalysis. Am Anthropol. 1993;95(1):51-72.
61. Pons $\mathrm{O}$, Petit RJ. Measuring and testing genetic differentiation with ordered vs. unordered alleles. Genetics. 1996:144(3):1237-45.

62. Yu Y, Harris AJ, He X. S-DIVA (statistical dispersal-vicariance analysis): a tool for inferring biogeographic histories. Mol Phylogenetics Evol. 2010;56:848-50.

63. Fu YX. Statistical tests of neutrality of mutations against population growth, hitchhiking and background selection. Genetics. 1997;147(2):915-25.

64. Tajima F. Statistical method for testing the neutral mutation hypothesis by DNA polymorphism. Genetics. 1989;123(3):585-95.

65. Rogers $A R$, Harpending $H$. Population growth makes waves in the distribution of pairwise genetic differences. Mol Biol Evol. 1992;9(3):552-69.

66. Excoffier $\mathrm{L}$, Lischer HEL. Arlequin suite version 3.5: a new series of programs to perform population genetics analyses under Linux and windows. Mol. Ecol. Resour. 2010;10(3):564-7.

67. Cornuet JM, Pudlo P, Veyssier J, Dehne-Garcia A, Gautier M, Leblois R, Marin JM, Estoup A. DIYABC v2.0: a software to make approximate Bayesian computation inferences about population history using single nucleotide polymorphism, DNA sequence and microsatellite data. Bioinformatics. 2014; 30(8):1187-9.

\section{Publisher's Note}

Springer Nature remains neutral with regard to jurisdictional claims in published maps and institutional affiliations.
Ready to submit your research? Choose BMC and benefit from:

- fast, convenient online submission

- thorough peer review by experienced researchers in your field

- rapid publication on acceptance

- support for research data, including large and complex data types

- gold Open Access which fosters wider collaboration and increased citations

- maximum visibility for your research: over $100 \mathrm{M}$ website views per year

At BMC, research is always in progress.

Learn more biomedcentral.com/submissions 